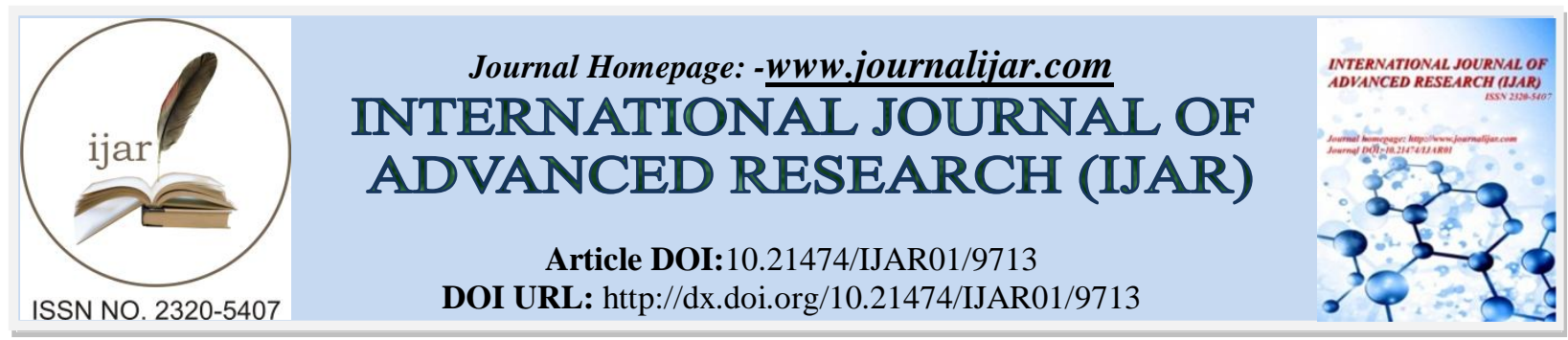

RESEARCH ARTICLE

\title{
SLIDING MODE CONTROL DESIGN FOR CONTINUOUS YEAST FERMENTATION PROCESS.
}

\author{
B. B. Musmade, R. A. Deshpande and Amit R. Gangad.
}

Dept. of Instrumentation and Control Engineering D Y Patil College of Engineering Akurdi, Pune-411044.

\section{Manuscript Info}

Manuscript History

Received: 08 July 2019

Final Accepted: 10 August 2019

Published: September 2019

Key words:-

Continuous yeast fermentation, glucose concentration, ethanol concentration, sliding mode control.

\begin{abstract}
Fermentation is known to be highly nonlinear process. The problem of controlling them by using conventional controllers has been widely studied; in spite of the extensive work on self tunning controllers there are many problems in the processing industries for which current techniques are inadequate. This paper presents the application of sliding mode controller with First-Order-Plus-Dead-Time model approach to a continuous yeast fermentation process in wine making. Objective is to control the temperature of fermenter by controlling the jacket flow rate. The effect of change in the temperature on the concentration of yeast, concentration of glucose and concentration of alcohol are analyzed. This approach results in fixed structure controller with a set of tuning equations as a function of the characteristics parameter of the model. The simulation results of the SMCr are compared with the PI controller for setpoint changes and load disturbance changes and have shown that $\mathrm{SMCr}$ is better and more versatile.

Copy Right, IJAR, 2019,. All rights reserved.
\end{abstract}

\section{Introduction:-}

The chemical processes in general, and biochemical fermentation systems in particular have strongly nonlinear features. Additionally the yeast fermentation process has its own regulatory mechanism due to these complexities performance of conventional controllers are not appropriate [1]. For continuous fermentation process, a sliding mode controller has been proposed. The concept of sliding mode control is based on varying the structure of the controller based on the changing state of the system in order to obtain a desired response. A high speed switching control action has been used to switch between different structures and the system state trajectory is forced to move along a chosen manifold in the state space, called the switching manifold. The behavior of the closed loop system is thus determined by the sliding surface $[3,4,5,7,8]$.

This paper is organized as follows. Section II briefly presents the process model of continuous yeast fermentation process in wine making with temperature control, Section III, presents basic concept of SMC and design of sliding mode controller (SMCr). Simulation results of SMCr are given in section IV and section V concludes the paper.

\section{Continuous Yeast Fermentation Process}

With the presence of living organisms, the control of fermentation process is more complex than conventional chemical reactor. The dynamics of the fermentation process are highly nonlinear and poorly understood. Besides being influenced by external conditions yeasts have their own regulatory mechanism, which mean that the model parameters may not remain unchanged over long time. Therefore we can only change the extracellular environment,

Corresponding Author:-B. B. Musmade.

Address:-Dept. of Instrumentation and Control EngineeringD Y Patil College of Engineering Akurdi, 
which we hope it would affect mechanism rightly [3]. Figure 1 depicts the continuous yeast fermentation process. The fermenter receives a stream, with unknown temperature, $T_{i}$ unknown glucose (feed substrate) concentration, $S_{f}$. Temperature of the fermenter, $T$ is controlled by manipulating the jacket flow rate, $F_{j}[1,6,9]$.

Few assumptions like Fermenter \& Jacket are perfectly mixed, Inlet stream is equal to outlet stream i.e. volume is constant, physical parameters, such as density and heat transfer coefficients are constant. Table 1 shows the steady state conditions and other operating information of the continuous yeast fermentation process [6].

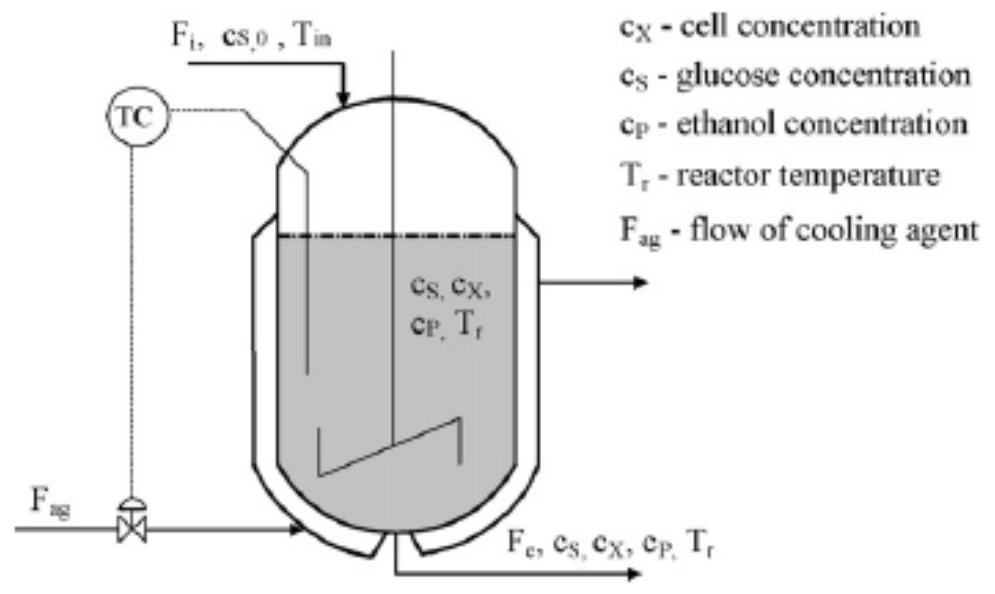

Fig 1:-Continuous yeast fermentation process

Table 1:-Steady State Values-Parameters of the process model

\begin{tabular}{|c|c|}
\hline Fermenter Volume, V & 1000 lit \\
\hline Yeast Concentration, $\mathrm{X}$ & $0.9 \mathrm{~g} / \mathrm{lit}$ \\
\hline Glucose Concentration, $\mathrm{S}$ & $29.7 \mathrm{~g} / \mathrm{lit}$ \\
\hline Ethanol Concentration, $\mathrm{P}$ & $12.5 \mathrm{~g} / \mathrm{lit}$ \\
\hline Jacket Temperature, $T_{j}$ & $29.33^{\circ} \mathrm{C}$ \\
\hline Fermenter Temperature, $\mathrm{T}$ & $27^{\circ} \mathrm{C}$ \\
\hline Inlet Flowrate, $\mathrm{F}_{\mathrm{l}}=$ Outlet Flowrate, $\mathrm{F}_{\mathrm{o}}$ & $51 \mathrm{lit} / \mathrm{hrs}$ \\
\hline Feed Substrate Concentration, $\mathrm{S}_{\mathrm{f}}$ & $60 \mathrm{~g} / \mathrm{lit}$ \\
\hline Inlet Temperature, $\mathrm{T}_{\mathrm{i}}$ & $25^{\circ} \mathrm{C}$ \\
\hline Flow rate of Jacket, $F_{j}$ & $20 \mathrm{lit} / \mathrm{hrs}$ \\
\hline Jacket Volume, $\mathrm{V}_{\mathrm{m}}$ & 25 lit \\
\hline Area of Heat Transfer, $A_{T}$ & $1 \mathrm{~m}^{2}$ \\
\hline Heat Transfer Coefficient, $K_{T}$ & $3.6 \mathrm{e} 5 \mathrm{~J} / \mathrm{hrm}^{2} \mathrm{~K}$ \\
\hline Density of the mixture, $\rho$ & $1080 \mathrm{~g} / \mathrm{lit}$ \\
\hline Density of cooling water, $\rho_{\mathrm{i}}$ & $1000 \mathrm{~g} / \mathrm{lit}$ \\
\hline Specific heat Capacity of mixture, $C_{P}$ & $4.18 \mathrm{~J} / \mathrm{gK}$ \\
\hline Sp. Heat Capacity of cooling water, $\mathrm{C}_{\mathrm{P}}$ & $4.18 \mathrm{~J} / \mathrm{gK}$ \\
\hline Activation energy for growth, $E_{a}$ & $55000 \mathrm{j} / \mathrm{mol}$ \\
\hline Activation energy for thermal death, $E_{d}$ & $220000 \mathrm{j} / \mathrm{mol}$ \\
\hline Constant of growth inhibition by ethanol, Kp & $0.139 \mathrm{~g} / 1$ \\
\hline Const. of fermentation inhibition by ethanol, Kp1 & $0.070 \mathrm{~g} / 1$ \\
\hline Constant in substrate term for growth, Ks & $1.030 \mathrm{~g} / 1$ \\
\hline Constant in substrate term for ethanol production, Ks1 & $1.680 \mathrm{~g} / 1$ \\
\hline Universal gas constant, $\mathrm{R}$ & $8.31 \mathrm{~J} / \mathrm{mol} . \mathrm{k}$ \\
\hline Growth yield coefficient for ethanol, Rsp & 0.435 \\
\hline Growth yield coefficient for cells, Rsx & 0.607 \\
\hline A1, pre-exponential factor in Arhenius equation & $9.5 \times 10^{8}$ \\
\hline
\end{tabular}


The process model is described by the following nonlinear differential equations $[1,2,6,9]$. The reactor is modeled as a continuous stirred tank with constant feed flow. Mass balance of yeast concentration is estimated as follows

$$
\frac{d X}{d t}=\mu_{x} X-D X
$$

where $\mathrm{D}$ is dilution rate in $\mathrm{hrs}^{-1}$ and $\mu_{\mathrm{x}}$ is specific growth rate in $\mathrm{hrs}^{-1}$.

$$
\mu_{x}=\frac{\mu_{m} S}{K_{s}+S} e^{-P / K_{p}}\left(A_{1} e^{-E_{a} / R T}-A_{2} e^{-E_{d} / R T}\right)
$$

Where $\mu_{m}$-Max. Specific fermentation rate $h^{-1}$. The growth rate model is a function of glucose concentration, alcohol concentration and temperature which is in ${ }^{\circ} K$. Alcohol is inhibitory for the yeast for the concentration above $5 \%$ [1]. In such case specific growth rate is multiplication of function of each factor.

Mass balance for the glucose concentration is,

$$
\frac{d S}{d t}=-\frac{\mu_{x} X}{R_{s x}}-\frac{\mu_{p} X}{R_{s p}}+D\left(S_{f}-S\right)
$$

where $\mu_{p}$ maximum specific fermentation rate $\left(\mathrm{h}^{-1}\right), \mu_{x}$ maximum specific growth rate $\left(\mathrm{h}^{-1}\right), \mathrm{R}_{\mathrm{sx}}$ and $\mathrm{R}_{\mathrm{sp}}$ are the growth yield coefficients for yeast and alcohol respectively. Mass balance for the product, ethanol concentration is,

$$
\frac{d P}{d t}=\mu_{p} X-D P
$$

Thermal balance for the fermenter

$$
\frac{d T}{d t}=\frac{\mu_{x} X}{\rho C_{P} Y_{H}}-\frac{K_{T} A_{T}}{\rho C_{P} V}\left(T-T_{j}\right)+D\left(T_{i}-T\right)
$$

where $\mathrm{Y}_{\mathrm{H}}$ is the is heat evolved per gram, g yeast/J and thermal balance for the jacket

$$
\frac{d T_{j}}{d t}=\frac{F_{j}}{V_{m}}\left(T_{j i}-T_{j}\right)+\frac{K_{T} A_{T}}{V_{m} \rho_{j} C_{P j}}\left(T-T_{j}\right)
$$

As we interested in ethanol for glucose consumption hence evolution of $\mathrm{CO}_{2}$ is not estimated in this model. Thus model consists of five differential equations.

Above material and energy balance equations that describe the behavior of continuous yeast fermentation process are non-linear, while commonly used control strategies are based on linear system theories. It is important, then to make these equations linear for control system design and analysis. So by Taylor series approximation the model is made linear [8]. Using the linearized model and the steady state operating values, transfer function is determined. Where time is estimated in hours. The transfer function thus obtained is then converted into FOPDT model by process reaction curve method $[3,5,7,8]$. It is given by

$$
G(s)=\frac{-0.146169}{16.2737 s+1} e^{-1.8706 s}
$$

Step response of the FOPDT model and the actual linearized process is compared in the figure 2. 


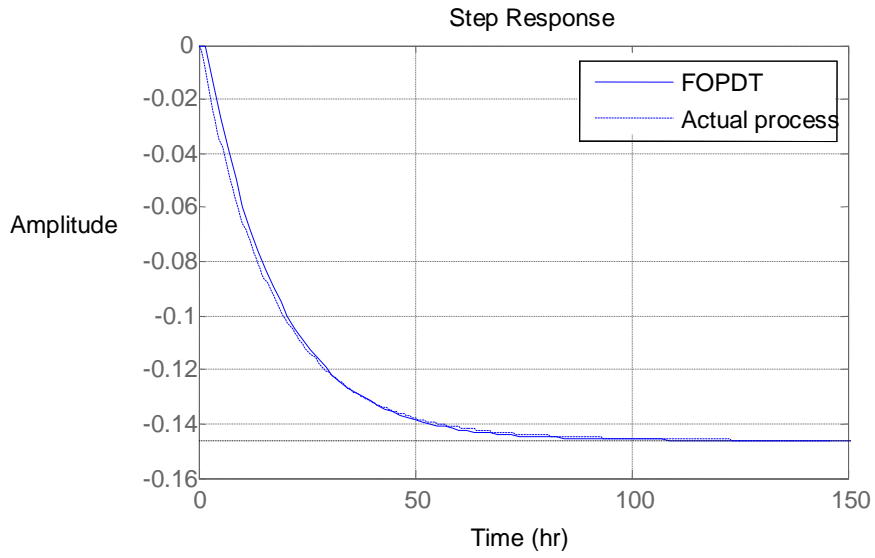

Fig 2:-Comparison of step responses of actual process \& FOPDT Model.

\section{Sliding Mode Control \\ Basic Concept of SMC}

Variable structure control systems are the class of systems whereby the 'control law' is deliberately changed during the control process according to some defined rules which depend on the state of the system [4]. In other words the control is allowed to change its structure, that is, to switch at any instant from one to another member of a set of possible continuous functions of the state. The variable structure design problem is then to select the parameters of each of the structures and to define the switching logic. Moreover, a VSS can possess new properties not present in any of the structures used. For instant, an asymptotically stable system may consist of two structures neither of which is asymptotically stable $[4,15,19,30]$. For the purpose of illustration consider double integrator with the feedback as shown in fig.3, where $\mathrm{K}$ is strictly positive.

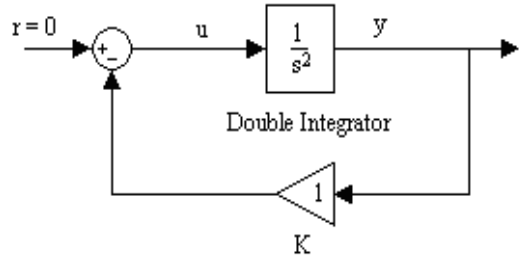

Fig 3:-Double integrator with feedback

$$
u(t)=-K y(t)
$$

For $\mathrm{K}=0.3$ and for $\mathrm{K}=3$ we have phase plots as shown in fig. 4 and fig. 5 respectively. From these phase plots; it is clear that in both the cases the control law is not appropriate since, the trajectory do not move towards the origin i.e. it is not asymptotically stable. In fig. 4 the trajectory is going closer to origin in $\mathrm{II}^{\text {nd }}$ and $\mathrm{IV}^{\text {th }}$ quadrants where as it is going away from the origin in $\mathrm{I}^{\mathrm{st}}$ and $\mathrm{III}^{\mathrm{rd}}$ quadrants. In fig. 5 the trajectory is going closer to origin in $\mathrm{I}^{\mathrm{st}}$ and $\mathrm{III}^{\mathrm{rd}}$ quadrants where as it is going away from the origin in $\mathrm{II}^{\text {nd }}$ and $\mathrm{IV}^{\text {th }}$ quadrants. However the asymptotic stability can be achieved if the structure of the system is changed on the coordinate axes, that is if the switching logic is

$$
u(t)= \begin{cases}-0.3 x_{1} & <0 \\ -3 x_{1} & <0\end{cases}
$$

This system clearly fits the description of a VSS given earlier. The phase plane plot for the closed loop system under the variable structure control is obtained by splicing together the appropriate regions from the two phase plane plots in fig. 4 and fig. 5. In this way the phase plane plot must spiral in towards the origin and an asymptotically stable motion results as shown in fig.6. That is by introducing a rule for switching between two control structures, which independently do not provide stability; a stable closed loop system has been obtained. 


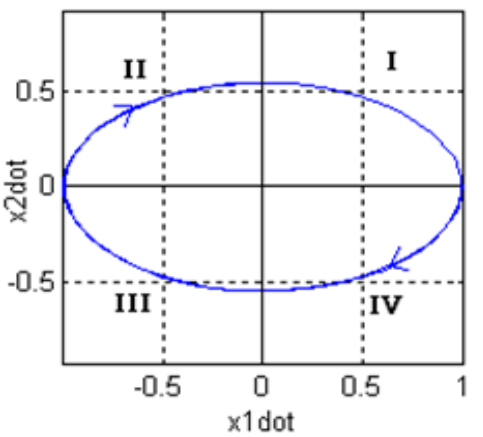

Fig 4:-Phase plane plot, $\mathrm{K}=0.3$

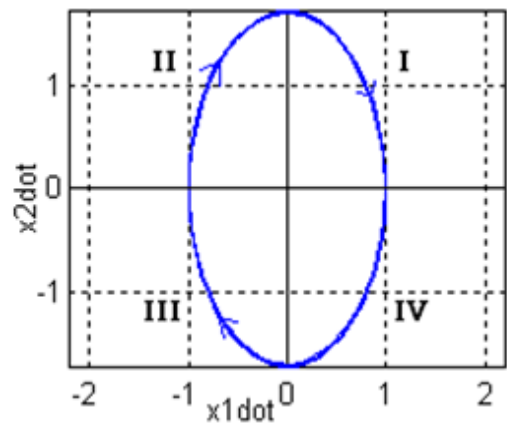

Fig 5:- Phase plane plot, $\mathrm{K}=3$

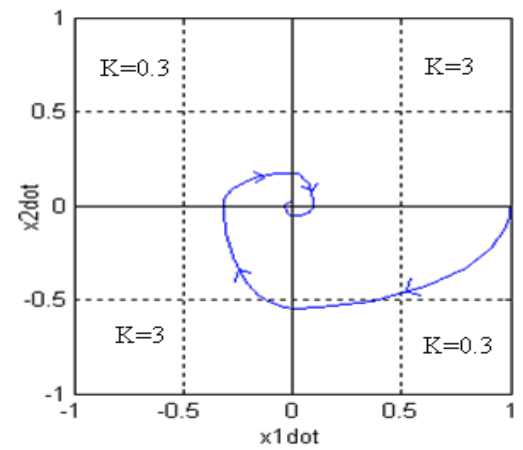

Fig 6:-Phase plane plot

In the above example, new system properties are obtained by compassing a desired trajectory from the parts of trajectories of different structures. An even more fundamental aspect of VSS is the possibility to obtain trajectories not inherent in any of the structures. The trajectories describe a new type of motion called sliding motion [1].

Process model relating the controlled and manipulated variables are generally of higher orders. The SMC procedure produces a complex controller for such models, which could contain four or more parameters resulting in difficult tuning job also the development of a complete model is difficult mainly due to the complexity of process itself and lack of knowledge of some process parameters. Hence a new approach for the design of Sliding Mode Controller (SMCr) based on First-Order-Plus-Dead-Time (FOPDT) model of process is presented in [4, 5].

\section{Development of Sliding Mode Controller (SMCr)}

The idea behind SMC is to define a surface along which the process can slide to its desired final value. The structure of the controller is intentionally altered as its state crosses the surface in accordance with the prescribed control law. The very first step in designing the SMCr is to choose the sliding surface, $s(t)$ to represent a desired global behavior for tracking performance. The $\mathrm{s}(\mathrm{t})$ selected in this work is an integro-differential equation acting on tracking error expression $[3,4,5,8,33]$.

$$
s(t)=\left(\frac{d}{d t}+\lambda\right)^{n} \int_{0}^{t} e(t) d t
$$

Where $\mathrm{e}(\mathrm{t})$ is tracking error i.e. $\mathrm{e}(\mathrm{t})=\mathrm{r}(\mathrm{t})-\mathrm{x}(\mathrm{t}), \lambda$ is tuning parameter and $\mathrm{n}$ is the order of the system.

The objective of the control is to ensure that the controlled variable be equal to its reference value at all times i.e. $\mathrm{e}(\mathrm{t})$ and its derivatives must be zero. Once the reference value is reached, $\mathrm{s}(\mathrm{t})$ reaches a constant value. To maintain $\mathrm{s}(\mathrm{t})$ at this constant value meaning that $\mathrm{e}(\mathrm{t})$ is zero at all times; it is desired to make

$$
\frac{d s(t)}{d t}=0
$$

The second step is to design the control law which drives the controlled variable to its reference value and satisfies equation (10). The SMC control law, $\mathrm{u}(\mathrm{t})$ consists of two additives parts a continuous part, $\mathrm{u}_{\mathrm{C}}(\mathrm{t})$ and discontinuous part, $\mathrm{u}_{\mathrm{D}}(\mathrm{t})$ which is given by equation (11)

$$
u(t)=u_{C}(t)+u_{D}(t)
$$

$\mathrm{u}_{\mathrm{D}}(\mathrm{t})$ incorporates a non-linear element that includes the switching element of control law. It is given by the equation (12) $[4,5]$.

$$
u_{D}(t)=K_{D} \frac{s(t)}{|s(t)|+\delta}
$$

with $\mathrm{K}_{\mathrm{D}}$ as tuning parameter responsible for reaching mode, $\delta$ as tuning parameter used to reduce chattering problem and $\mathrm{s}(\mathrm{t})$ is given by the equation (9). The tuning parameters $\mathrm{K}_{\mathrm{D}}$ and $\delta$ are determined by the following equations (13) and equation (14) respectively [5]. 


$$
\begin{aligned}
& K_{D}=\frac{0.51}{|K|}\left(\frac{\tau}{t_{0}}\right)^{0.76} \\
& \delta=0.68+0.12|K| K_{D} * 2 * \lambda
\end{aligned}
$$

Now for designing the controller first step is to propose a way to handle the dead time. It is approximated by Taylor series approximation as given by the equation

$$
e^{-t_{0} s} \cong \frac{1}{t_{0} s+1}
$$

Substituting this in FOPDT model we get equation

$$
\frac{X(s)}{U(s)}=\frac{K}{t_{0} \tau s^{2}+s\left(\tau+t_{0}\right)+1}
$$

In time domain we can write it as

$$
u(t)=\frac{t_{0} \tau}{K} \frac{d^{2} x(t)}{d t^{2}}+\frac{\left(t_{0}+\tau\right)}{K} \frac{d x(t)}{d t}+\frac{x(t)}{K}
$$

From this we can say that the order of the system is two i.e. sliding surface defined in the equation (9) will be given by the equation

$$
s(t)=\frac{d}{d t} e(t)+2 \lambda e(t)+\lambda^{2} \int_{0}^{t} e(t) d t
$$

Differentiating above equation (18) of sliding surface to get equation (10)

$$
\frac{d}{d t} s(t)=\frac{d^{2}}{d t^{2}} e(t)+2 \lambda \frac{d}{d t} e(t)+\lambda^{2} e(t)=0
$$

Again $e(t)=r(t)-x(t)$ and $\mathrm{r}(\mathrm{t})$ is the reference value which is constant. Hence derivative of the constant value is zero and the equation (19) reduces to

$$
\frac{d^{2} x(t)}{d t^{2}}=-2 \lambda \frac{d x(t)}{d t}+\lambda^{2} e(t)
$$

Putting above equation (20) in the equation (17) and solving we get the continuous part of the control law, $\mathrm{u}(\mathrm{t})$ as

$$
u_{C}(t)=\frac{t_{0} \tau}{K}\left(\left(\frac{\left(t_{0}+\tau\right)}{t_{0} \tau}-2 \lambda\right) \frac{d x(t)}{d t}+\lambda^{2} e(t)+\frac{x(t)}{t_{0} \tau}\right)
$$

We can simplify the controller by making derivative of controlled variable as zero by making assumption

$$
\frac{\left(t_{0}+\tau\right)}{t_{0} \tau}=2 \lambda
$$

Hence complete continuous part of the controller will be

$$
u_{C}(t)=\frac{t_{0} \tau}{K}\left(\lambda^{2} e(t)+\frac{x(t)}{t_{0} \tau}\right)
$$

Where as discontinuous part is given by the equation (22). Hence total control law will be given as

$$
u(t)=\frac{t_{0} \tau}{K}\left(\lambda^{2} e(t)+\frac{x(t)}{t_{0} \tau}\right)+K_{D} \frac{s(t)}{|s(t)|+\delta}
$$

Where from the equation (28) we can write sliding function as

$$
s(t)=\operatorname{sign}(K)\left[\frac{-d x(t)}{d t}+2 \lambda e(t)+\lambda^{2} \int_{0}^{t} e(t) d t\right]
$$

Equations (24) \& (25) constitute controller equations to be used. These equations present advantages from process control point of view, first they have a fixed structure depending on the $\lambda$ and characteristic parameters of the FOPDT model, and second the action of the controller is considered in the sliding surface equation, by including the term sign $(\mathrm{K})$. 


\section{Simulation Results:-}

For system s-function is developed in MATLAB and the open loop response is studied. Effect of increase and decrease of flowrate of jacket, $F_{j}$ and increase and decrease of inlet temperature, $T_{i}$ on output variables is examined and it is observed that with increase of $F_{j} \& T_{i}$ all the variables increases except $S$ and on decrease of $F_{j} \& T_{i}$ all the variables decreases except $\mathrm{S}$.

For continuous yeast fermentation process the SMCr is designed by the procedure explained in the section II. The tuning parameters are calculated and these are $\mathrm{K}_{\mathrm{D}}=18.0609, \delta=0.8688$, and $\lambda=0.2981$. The simulation of the $\mathrm{SMCr}$ is given in figure 7. The result of the SMCr is compared with the PI controller. Parameters of the PI controller are determined by the open loop method of Ziegler Nichols. These are $\mathrm{K}_{\mathrm{C}}=-53.56$ and $\tau_{\mathrm{i}}=6.1730 \mathrm{hrs}$, where $\mathrm{K}_{\mathrm{C}}$, and $\tau_{\mathrm{i}}$ are the proportional and integral constants of PI controller respectively. Figure 7 shows the closed loop performance when the process is subjected to the change in disturbance input (inlet temperature). Figure 7(a) shows the effect of step change to inlet temperature $\left(+25 \%\right.$ of set point temperature at $\left.32{ }^{\circ} \mathrm{C}\right)$ and in figure $7(\mathrm{~b})$ the effect of step change to inlet temperature $\left(-25 \%\right.$ of set point temperature at $\left.32{ }^{\circ} \mathrm{C}\right)$ shown.

When the set point temperature is $32{ }^{\circ} \mathrm{C}$ it is observed that the response of SMCr does not deviates much from the set point when the disturbance is introduced, but response of PI controller deviates from the set point. This deviation is very small and acceptable as the effect of this disturbance on yeast concentration, glucose concentration and alcohol concentration is negligible. This deviation changes the yeast concentration, glucose concentration and alcohol concentration. Ultimately it degrades the quality of wine. When the set point temperature is $32^{\circ} \mathrm{C}$ it is observed that the response deviates from the set point, but the deviation is very small in case of $\mathrm{SMCr}$, whereas in case of PI controller the deviation is very large.

Also when control input in eqn. (24) is used for simulation, it is seen from figure 8(a) that system states (Fermenter Temp. \& Rate of change of Fermenter Temp.) settles to zero. Figure 8(b) shows the phase plot. Figure 8(c) Control input and figure 8(d) Switching surface.
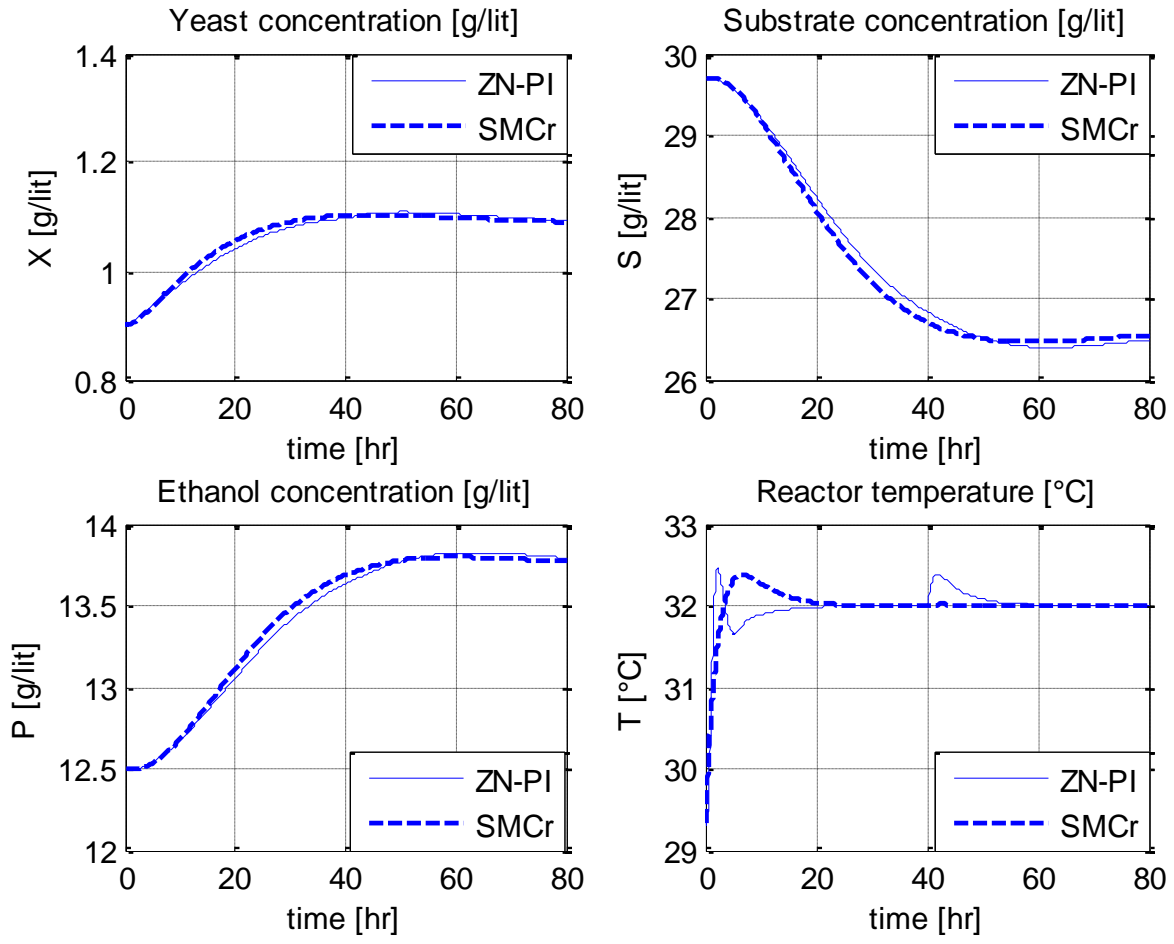

Figure 7:-(a) $+25 \%$ increase in the inlet temperature at $32{ }^{\circ} \mathrm{C}$ 

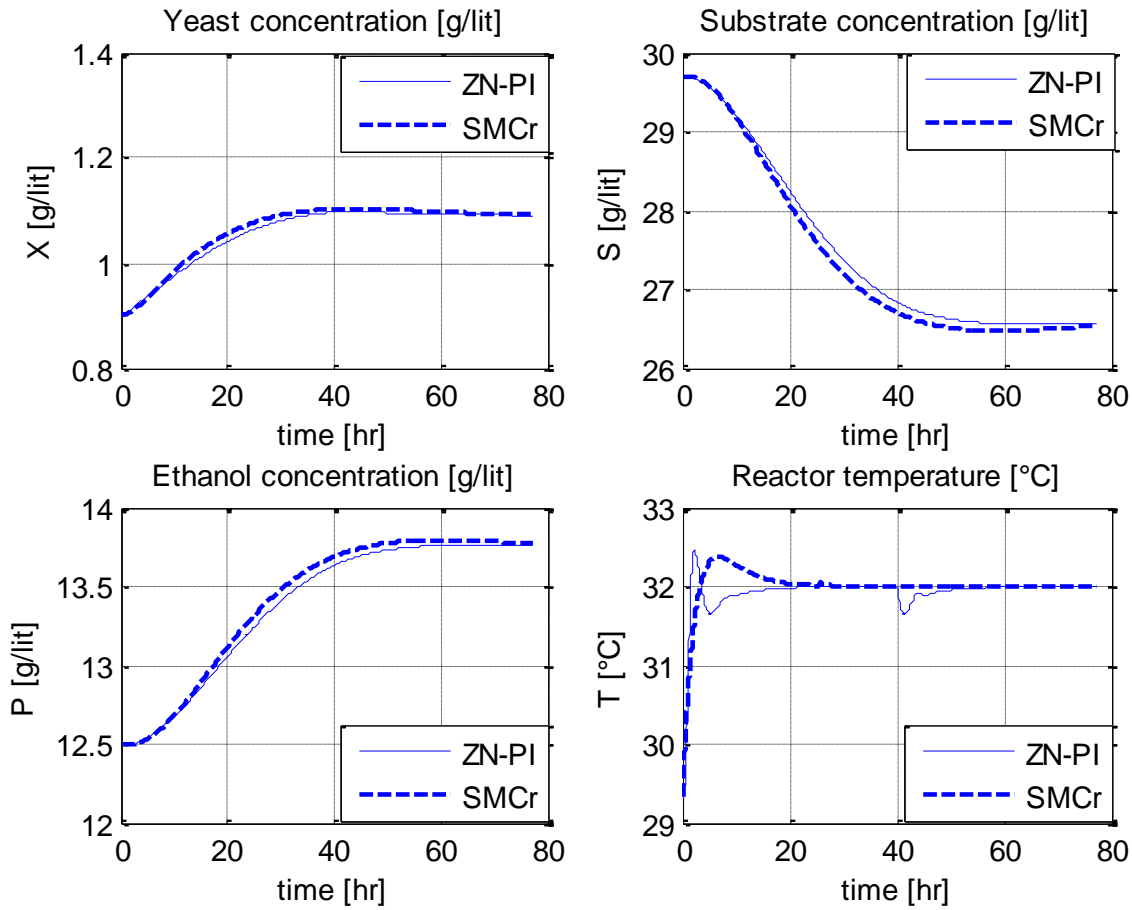

Figure $7(\mathrm{~b})-25 \%$ decrease in the inlet temperature at $32{ }^{\circ} \mathrm{C}$

Figure 7:-The response of fermenter when subjected to the change in disturbance input (inlet temperature).

(a) System states

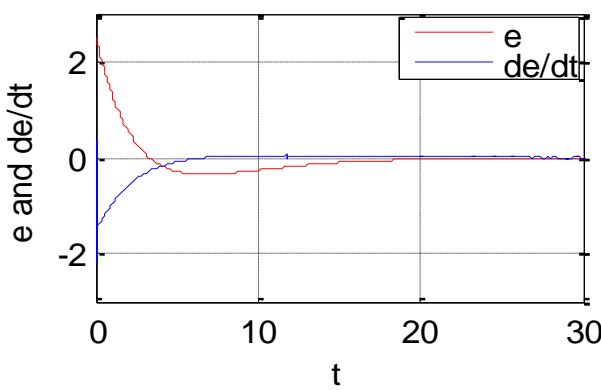

(c) Control input

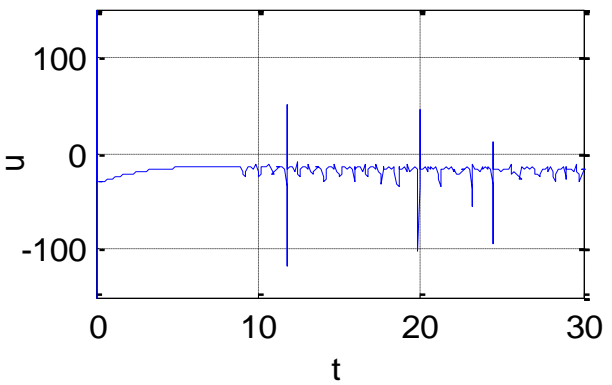

(b) Phase plot

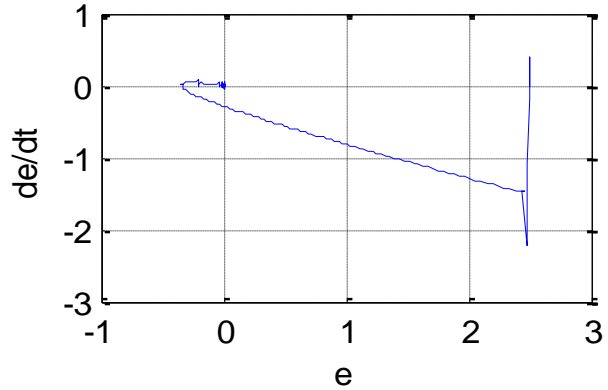

(d) Switching surface

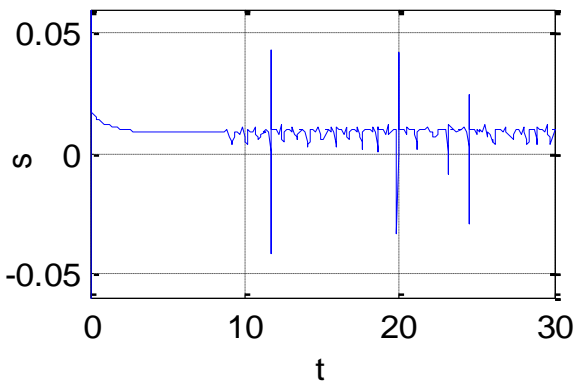

Figure 8:-Response of the system with control law; (a) System states, (b) Phase plot, (c) Control input, (d)

Switching surface

\section{Conclusion}

The purpose of this paper is to present a SMC based on FOPDT models, to control temperature of continuous yeast fermentation process in wine making. After determining the model of fermentation process by process reaction curve method, SMC based scheme is formulated. The proposed controller is tested for the setpoint change and disturbance rejection. Simulations are presented and it is found that $\mathrm{SMCr}$ performance is stable and quite 
satisfactory in spite of nonlinearities over wide range. It can be concluded that the proposed SMCr yielded a better dynamic performance than conventional PI controller in terms of setting time, maximum overshoot and steady state error.

\section{References}

1. Z. K. Nagy, "Model Based Control of a Fermentation Bioreactor using Optimally Designed Artificial Neural Networks", Chemical Engineering Journal, 127, 95-109, 2007.

2. B. Wayne Bequette, "Process Control and Modeling, Design and Simulation", Prentice Hall of India, pp. 619639.

3. Oscar Camacho, Carlos A. Smith.: "Sliding Mode Control: an Approach to Regulate Nonlinear Chemical Processes", ISA Transaction Vol. 39, 2000, pp. 205-18.

4. Hung J. Y., Gao W., and Hung J. C., "Variable Structure Control: A Survey", IEEE Trans, on Industrial Electronics, Vol. 40, No. 1, February 1993, pp. 2-22

5. Oscar Camacho, Ruben Rojas, Weinston, "Variable Structure Control Applied to Chemical Processes with Inverse Response", ISA Transaction Vol. 38, 1999, pp. 55-72.

6. S. Aiba, M. Shoda, M. Nagatani, "Kinetics of product inhibition in alcoholic fermentation", Biotechnology Bioengineering 10 (1968) 846-864.

7. O. Camacho, C. Smith, Application of sliding mode control to nonlinear chemical processes with variable deadtime, in: Proceedings of 2nd Congress of Colombian Association of Automatics, Colombia, 1997, 122-128.

8. O. Camacho, C. Smith, E. Chacon, "Toward an implementation of sliding mode control to chemical processes" Proceedings of ISIE'97, Guimaraes, Portugal, 1997, 1101-1105.

9. M. L. Shuler, "Bioprocess Engineering Basic Concepts", $2^{\text {nd }}$ Edition, Pearson Education, 2005.

10. V.I. Utkin, "Variable structure systems with sliding modes", Transactions of IEEE on Automatic Control $\mathrm{AC}(22)(1977)$ 212-222.

11. Y.H. Roh, J.H. Oh, "Sliding mode control with uncertainty adaptation for uncertain input-delay systems", Int. Journal on Controls, 73 (2000) 1255-1260.

12. Q.G. Wang, Y. Zhang, X. Guo, "Robust closed-loop identification with application to auto-tuning", Journal Process Control, 11 (2001) 519-530.

13. J. Hu, J. Chu, H. Su, "SMVSC for a class of time-delay uncertain systems with mismatching uncertainties", IEE Proc. Control Theory Appl. 147 (2000) 687-693.

14. A. Aoyama, F.J. Doyle, Venkatasubramsinion, "Neural network approach for non-minimum-phase nonlinear process control", Journal Process Control, 6 (1) (1995) 17-26.

15. O. Camacho, R. Rojas, "A general sliding mode controller for nonlinear chemical processes", J. Dynamic System Measurement Control, 122 (2000) 650-655.

16. J.Y. Choi, J. Lee, J. H. Jung, M. Lee, C. Han, "Sequential loop closing identification of multivariable process models", Comput. Chem. Eng. 24 (2000) 809-814.

17. C.H. Chou, C.C. Cheng, "Design of adaptive variable structure controllers for perturbed time-varying state delay systems", J. Franklin Inst. 338 (2001) 35-46.

18. A.S. Zinober, "Variable Structure and Liapunov Control", Spring-Verlag, London, 1994.

19. T. E. Marlin, Process Control, McGraw-Hill, New York, 1995.

20. S.H. Hwang, "Adaptive dominant pole design of PID controllers based on a single closed-loop test", Chem. Eng. Commun. 124(1993) 131-152.

21. S.W. Sung, J. O, I.B. Lee, J. Lee, S.H. Yi, “Automatic tuning of PID controller using second-order plus time delay model", J.Chem. Eng. Jpn. 29 (1996) 990-999.

22. A. Kojima, K. Uchida, E. Shimemura, S. Ishijima, "Robust stabilization of a system with delayed in control", IEEE Trans. Automat. Control 39 (1994) 1694-1698.

23. Y.H. Roh, J.H. Oh, "Robust stabilization of uncertain input-delay systems by sliding mode control with delay compensation", Automatica, 35 (1999) 1861-1865.

24. O. Camacho, C. Smith, W. Moreno, "Development of an internal model sliding mode controller", Ind. Eng. Chem. Res. 42 (2003) 568-573.

25. J.H. Park, H. I. Park, I.B. Lee, "Closed-loop on-line process identification using a proportional controller", Chem. Eng. Sci. 53 (1998) 1713-1724.

26. S.M. Fang, S.J. Shiu, S.H. Hwang, "Sequential design methodology for multivariable control systems", in: Symposium on Computer Process Control, Taipei, Taiwan, 1994, pp. 26-33. 